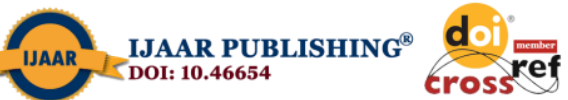

International Journal of Advanced Academic Research (Sciences, Technology and Engineering) | ISSN: 2488-9849 Vol. 6, Issue 7 (July, 2020) | www.ijaar.org

Journal DOI: 10.46654/ij.24889849

Article DOI: 10.46654/ij.24889849.a6725

\title{
IMPROVEMENT OF TEACHERS' PROFICIENCY IN MATHEMATICAL LANGUAGE FOR SUCCESSFUL MATHEMATICS LEARNING OUTCOME
}

\section{OSUO-SISEKEN UZOMA OGUGUO}

Department of Mathematics, Federal College of Education (Technical), Omoku, Rivers-State.

Email: dokufunmi@yahoo.com

\begin{abstract}
Language of instruction in teaching and learning holds a central place in students' achievement as it influences performance. Students' fluency in language of instruction and achievement in mathematics is highly dependent on the teacher's level of proficiency, mastery, fluency and appropriate use of mathematical language. This paper reiterates the need for teachers' proficiency in mathematical language. The definition of language, meaning of mathematical language, nature of mathematical language and the need for teachers proficiency in mathematical language is discussed. Based on the discussion, the study recommended among other things that a course on mathematical language should be introduced at higher educational programmes, especially teacher training institutions, teachers should be on trainre-train programmes on mathematical language, teachers should identify and define terms, phrases, symbols, etc. related to the mathematical content or topic to be taught in their lesson plan, teachers should explain these terms, phrases, symbols etc. to the learners before proceeding to apply them for their lesson, sensitization of teachers on the importance of correct language usage in mathematics instruction delivery should be enforced.
\end{abstract}

Keywords: Language, Mathematics, teacher's language proficiency. 


\section{Introduction}

Challenges of development worldwide have been reduced drastically through the advancement of Science, Technology and Engineering. Science which is regarded as the body of knowledge that is verifiable and applied in the solution of every day challenge of life has its foundation in mathematics. Competency in mathematics is the key towards the goal of establishing a scientific and technological oriented society (Veloo, Krishnasamy \& Abdulla, 2015). This implies that no Society can achieve the goal of establishing a scientific and technological oriented society without competent mathematics teachers. The goal of Mathematics education is to develop students' problem-solving and reasoning abilities, improve their capacity to transfer knowledge and ensure they can correctly use Mathematics Language (National Council of Teachers of Mathematics (NCTM) 2000). This cannot be achieved without teacher's proficiency in mathematical language as the saying goes "you cannot give what you don't have". Effective Mathematics teaching can be actualized only with correct use of the mathematical content language which comprises mathematical rules, concepts, symbols and terms (Gürefe, 2018). Mathematics Language is a distinct register within a natural language (for example English language), which is described as "a set of meanings that is appropriate to a particular function of language, together with the words and structures which express these meanings" (Halliday,1975). He further noted that once the register is mastered, learners will have the ability to listen, question and discuss together with the ability to read and record.

Gürefe (2018) carried out a study on Mathematical Language skills of Mathematics Prospective Teachers to examine their content language skills in some basic geometric concepts. The result of the findings showed among others that prospective teachers were not able to use the mathematical language adequately and usually not able to explain the concepts using symbols, mistakes on the verbal level that prospective teachers used to explain the concepts in the research. Tout (1991 in Meiers, 2010) reported how analysis of words and phrases used for the operations of addition, subtraction, multiplication and division indicates how complicated it is for adults to solve problems and interpret real life situations.

Competency in the language of instruction is a necessary requirement for understanding the concepts being taught (Phakite, Hirsh and Woodrow, 2013). One of the most important element for ensuring that students can learn mathematics is teachers' sufficiency of knowledge and their ability to convey that knowledge with an adequate language which requires teachers to use mathematical language effectively during lessons (Raiker in Güreje, 2018). Lack of integration of language and content development contributes to the lack of active engagement by students in mathematics classrooms (Brenner, 1998). Many children see mathematics as a foreign language, the symbols and expressions provide a formidable barrier to understanding mathematical symbols (National Numeracy Review Report (NNRR, 2008). This barrier can be eliminated with teacher's sufficient and appropriate use of mathematical language. Achievement in mathematics is highly related to students' understanding of mathematical language (Mbugua, 2012). It is evident from studies that the language of mathematics influences students' achievement in the subject.

The study is aimed at exploring the meaning of Language, Mathematical Language, Nature of Mathematical Language and the place of improvement of mathematics Teachers proficiency in the language of mathematics in successful learning outcome in mathematics. 


\section{Definition of Language}

Language is (1) a Systematic means of communicating by the use of sounds or conventional symbols. (2) A system of words used in a particular discipline. (3) A system of abstract codes which represent antecedent events and concepts. (4) The code we all use to express ourselves and communicate to others. (5) A set (finite or infinite) of sentences, each finite in length and constructed out of a finite set of elements. These definitions describe Language in terms of the following components; (1) A vocabulary of symbols or words. (2) A grammar consisting of rules of how these symbols may be used. (3) A syntax or propositional structure which places the symbols in linear structures. (6) A discourse or narrative, consisting of strings of syntactic propositions. (7) A community of people who use and understand these symbols. (8) A range of meanings that can be communicated with these symbols. Each of these components is also found in the Language of Mathematics (https://en.wikipedia.org/wiki/language_of_mathematics). Kharde (2016), defined Language as ways of transferring information and meaning. Language is a system of sending or receiving information which is either spoken or converted in written or signed form, its ease of use aids people in rational thoughts (Alt, Arizmendi, Nippold \& Prult-Lord, 2014). Language is a system of arbitrary vocal symbols by means of which a social group co-operates (Bloch \& Fraser in encyclopedia Britannica). Language is a system of communication which is either spoken or encoded in written or signed form; its fluency aids an individual in logical thinking (Mbugua, 2012).

\section{Meaning of Mathematical Language}

Mathematics as a discipline has its own language which is categorized as academic language. Miller (1993) described Mathematics as a specialized language. Mathematics is a language which is concise and precise (Mutunga \& Breakwell, 1992 in Wanjiru, 2015) which consists of both terminologies (vocabulary) and symbols. It is a universal language with syntactical and rhetorical structures (Wanjiru, 2015). Its rhetorical structures consist of indefinite terms, definite terms, axioms and theorems (Aiken, 1972). Mathematical Language ensures mutual communication between individuals through concepts, terms, symbols and grammar. Hence, mathematical language can be defined as the channel or medium through which mathematical ideas and information are being expressed, communicated and shared.

\section{Nature of Mathematical Language}

Mathematics as a language has its characteristics and peculiarities just as any other language. It is a system of communication with its own set of symbols, convection or special words namely Mathematical terms such as product, reflection, angle, determinant etc. Symbols such as $\mu, \leq, \pi, \neq, \sqrt{ }, \sum, \theta$ etc., and Mathematical structures such as $=\pi r^{2},=\frac{-b \pm \sqrt{b^{2}-4 a c}}{2 a}, a^{2}+b^{2}=$ $c^{2}, \sin \alpha \pm \sin \beta=2 \sin \frac{1}{2}(\alpha \pm \beta) \cos \frac{1}{2}(\alpha \mp \beta)$, etc. With the use of Mathematical language, very good distinctions are made, things are said briefly and complex thoughts are expressed with relative ease. Mathematical Language involves the use of everyday English. Such words as degree, difference, base, angle, greater than, change, average, root, sign, table, times, differentiation, face, improper, odd, even, parallel, volume, capacity, etc used in mathematics instruction delivery which are also used in every day English tends to be ambiguous due to having one meaning in the mathematics register and a different meaning in everyday usage.. Also, Mathematics Language consists of specific terms. These specific terms are terms which are only encountered while in Mathematics environment, examples are quadrilateral, polygon, 
parallelogram, pie, adjacent, circumference, hypotenuse, obtuse, etc. The language of Mathematics also includes many words that sound the same as words with other meanings (or homophones). Examples are represented in the table below:-

Table1: Mathematical words and homophonic partner

\begin{tabular}{|l|l|l|}
\hline S/N & Mathematical Term & Homophones \\
\hline 1. & Arc & Ark \\
\hline 2. & Chord & Cord \\
\hline 3. & Mode & Mowed \\
\hline 4. & Pi & Pie \\
\hline 5. & Plane & Plain \\
\hline 6. & Serial & Cereal \\
\hline 7. & Sine & Sign \\
\hline 8. & Sum & Some \\
\hline
\end{tabular}

Adapted from Adams, Thanagatah and King (2005)

Mathematical Language includes words that have the same spelling, pronunciation as everyday English words but different meaning as Mathematical terms. Some Examples of such words are, rank, real, point, change, mass, root, power, product, prime, even, odd, concrete.

In learning mathematics, one is required to interpret the mathematical text and convert it to an appropriate symbolic representation and perform mathematical operations with the symbols. The symbols in mathematics provide structure, allow manipulation and provide for reflection on the task completed. Examples of mathematical symbols are: $+,-,=,<,>, \geq, \leq, \neq, \pm, \sqrt{ },{ }^{\theta}$, etc. Some of the mathematical symbols have multiple words associated to them, for example

Table 2: Mathematical Symbols and associated words

\begin{tabular}{|l|l|l|}
\hline S/N & Symbol & Associated words \\
\hline 1. & + & Plus, addition, sum of, total, increase, etc \\
\hline 2. & - & Minus, subtract, difference, reduced by, decrease, etc. \\
\hline 3. & $\times$ & Times, multiply, product, etc \\
\hline 4. & $=$ & Equal to, equality, the same, result, outcome, etc. \\
\hline 5. & $<$ & Less than, smaller than, etc. \\
\hline
\end{tabular}

Also, symbols that look the same may not mean the same in different contexts and symbols that look different may have the same meaning in different context. For instance, in the study of vectors, the dot product $(\cdot)$ and the cross product $(\times)$ symbols look the same as the multiplication symbol in arithmetic and Algebra but have different meaning when working with vectors.

Mathematical language has its peculiar grammar, syntax, vocabulary, word order, synonyms, negations, conventions, abbreviations, sentence structure and paragraph structures. Technical terms such as equivalent, quotient, probability factor, frequency, line amongst others which are specific to mathematics are used in the process of teaching and learning mathematics. Specialist syntax such as "and, of, or, a, if" are used to define mathematical structures which are then used in expressing logical relationships. 


\section{Teachers' Mathematical Language Proficiency and Successful Mathematics Learning Outcome}

The alarming rate of students' poor performance in Mathematics at internal and external examinations has continuously kept researchers, stakeholders on the lane of ascertaining the cause and proffering solution. Many researchers have noted the need to focus on teacher's adequacy and competency with respect to their pedagogical practices, strategies, mastery of the curriculum and subject contents (Chall \& Popp, 1990 cited in Wanjuri, 2015; Stuart, 2004; Rodgers, 2001 in Akinsolu, 2010). Similarly, several findings have shown that teachers are major determinant of students' academic achievements (Iji \& Uka, 2013; Agyemang, 1993; Ijaiya, 1998).

According to Danyer \& Villeges (1993), the essence of teaching is for human interaction and that all teachers must continuously refine to enhance their skills of communication and collaboration. This implies that the goal of teaching cannot be achieved without sufficient, appropriate and effective communication skills. Effective communication requires language sufficiency and appropriateness.

In communicating mathematics effectively, the teachers role is central and hence the necessity for him/her to be well equipped with the language of mathematics. Research has shown that teacher's fluency in mathematical language determines the extent of student's achievement in mathematics (Phakite, Hirsh \& Woodrow, 2013; Mbugu, 2012; Gürefe, 2018).

Mathematics is a complex and compact symbol system and unless meanings are attached to those symbols, mathematics becomes literally meaningless to children (National Council of Teachers of Mathematics, 1989). According to Curcio (1990 cited in Mutugua, 2012) learning mathematics requires development of a mathematics language in which abstraction of mathematical concepts can be made. If the teacher, who is central in instruction delivery, lacks proficiency in mathematical language, then it will hamper learner's development of mathematical concepts which could make learners dread the subject.

Every mathematics teacher is a language teacher, particularly the academic language used to formulate and communicate mathematics learning (Lager, 2006). This implies that mathematics teachers must have sufficient knowledge of mathematical language and the skill to appropriately use them for achievement of set goals. Teacher's proficiency in mathematical language will reduce misconceptions and misunderstanding amongst learners of mathematics which will minimize confusion, frustration and hatred for the subject resulting in successful learning outcome. Mathematics language proficiency amongst teachers will reduce difficulty in understanding, analyzing and communicating mathematics ideas amongst learners which is a bases for the recommendation by the National Numeracy Review Report (2008), that language and literacies of mathematics be explicitly taught by all teachers of mathematics in recognition that language can provide a formidable barrier to both the understanding of mathematics concepts and to provide students access to assessing items aimed at eliciting mathematical understanding. Mbugua (2012) in the study "Influence of mathematical language on achievement in mathematics, reported that achievement in mathematics is highly related to students understanding of mathematical language. He further noted that students make mistakes when solving mathematics problem due to lack of understanding of mathematical language which is as a result of teachers' deficiency in mathematical language. Similarly, Wood (1998 in 
Mutugua, 2012) observed that children might fail to solve a problem just because they do not understand what is being said to them.

Teachers' proficiency will develop in the learners the ability and capacity to describe mathematical ideas and concepts using appropriate language. It will demystify mathematics whose structure and language when not appropriately used can generate dislike among learners for the subject. Teachers' fluency and appropriate use of mathematical language will create in learners the ability to work out meanings, develop further thinking and applying mathematical knowledge in solving real life problem. It will also make mathematics learning flexible, easy and enjoyable. Thus, in order to achieve the desired learning outcome in mathematics, the teacher who is at the center of instruction delivery must have a good command of mathematical language.

\section{Conclusion}

The process of teaching and learning entails communication which involves a language. To achieve the objectives of teaching and learning, both the teacher and the learner must be very fluent in the language of communication and instruction. Mathematics as a discipline has its own language which incorporates all the features of a language. These language components of mathematics and the nature of mathematics language must be mastered by the teacher for effective teaching of the subject and achievement in mathematics amongst learners in order to reduce the consistent high failure rate of students in the subject.

\section{Recommendation}

Based on the discussion above and the vital role teachers proficiency in mathematics language plays in the effective teaching, learning and achievement in mathematics, the following recommendations are made:

1. A course on mathematical language should be introduced at higher educational programmes, especially teacher training institutions.

2. Teachers should be on train-re-train programmes on mathematical language.

3. Teachers should identify and define terms, phrases, symbols, etc. related to the mathematical content or topic to be taught in their lesson plan.

4. Teachers should explain these terms, phrases, symbols etc. to the learners before proceeding to apply them for their lesson.

5. Workshops and seminars should be organized for teachers to keep them informed of new innovations in mathematics language and applications.

6. Sensitization of teachers on the importance of correct language usage in mathematics instruction delivery should be enforced. 


\section{References}

Adams, T.L; Thangata, F. \& King, C. (2005). "Weigh" to go! Exploring Mathematical Language. Mathematics Teaching in the Middle School. 10(9): 444-448.

Agyemang, D.K.(1993). Sociology of Education for African Students: Temo:Ghana Publishing Corporation.

Aiken, L.R.(1972). Language Factors in Learning Mathematics Test. Applied Measurement in Education. 14(3): 219-213.

Akinsolu, A.O.(2010). Teachers and Students' Academic Performance in Nigerian Secondary Schools: Implication for Planning. Florida Journal of Educational Administration and Policy. 3(2): 86-103.

Brenner, M.E. (1998). Adding Cognition to the Formular for Culturally Relevant Instruction in Mathematics. Anthropology and Education. 29(2): 214-244.

Bloch, B and Trager, G.L. Definition of Language. Retrieved from https://www.britannica.com/topic/language on 12/03/2020.

Gurefe, N. (2018). Mathematical Language of Prospective Teachers. Universal Journal of Educational Research. 6(4): 661-671.

Ijaiya, N.Y.S. (1998). An Investigation into the Problem of Teachers Management in Kwara State Secondary Schools. Studies in Educational Planning and Administration. 1(2): 4958 .

Kharde, U. (2016). The Symbolic Language of Mathematics.The Explorer. 1(1): 117-118.

Larger, E.A. (2006). Types of Mathematical Language Reading Interactions that Unnecessarily Hinder Algebra Learning and Assessment. Reading Psychology. 27, 165-204.

Mbugua, Z.K. (2012).Influence of Mathematical Language on Achievement in Mathematics by Secondary School Students in Kenya. International Journal of Education and Information Studies. 2(1): 1-7.

Meiers, M. (2010).Language in Mathematics Classroom. The Digest, NSWIT, 2010(2). Retrieved on 20/10/2019 from http://www.nswteachers.nsw.edu.au

Miller, D.L.(1993). Making the Connection with Language.Arithmetic Teacher. 40(6): 311-316.

National Council of Teachers of Mathematics.(2000). Principles and Standards for Schools. Retrieved from http://www.nctm.org/standards

National Numeracy Review Report (2008). Retrieved from http://www.voced.edu.au/content/ngv\%3A19994

Pimm, D. (1987). Speaking Mathematically: Communication in Mathematics Classroom.London:Routledge and Kegan Paul Ltd. 
Veloo, A; Krishnasamy, H.N \& Abdullah, W.S.W (2015).Types of Students Errors in Mathematical Symbols, Graphs \& Problem Solving. Asian Social Science.11(15),324334 .

Wanjiru, B.N. (2015). Effect of Mathematical Vocabulary Instruction on Students Achievement in Mathematics in Secondary Schools of Muranga County,Kenya.Unpublished M.Ed Thesis, Kenyatta University, Nairobi. 